\title{
A pluralidade da cobertura jornalística no interior de São Paulo: a experiência do Jornal Dois com a mídia radical em Bauru
}

\section{The Plurality of Media Coverage in the Interior of São Paulo: Jornal Dois's Experience with Radical Media in Bauru}

\section{Ana Carolina Moraes dos Santos ${ }^{1}$, Lorenzo Santiago ${ }^{2}$, Lucas Eduardo Tozzi Mendes ${ }^{3}$}

Resumo: Este artigo propõe uma reflexão sobre a pluralidade da cobertura jornalística no interior do Estado de São Paulo relatada a partir da experiência do Jornal Dois, uma mídia independente de Bauru. O jornal surgiu com uma proposta disruptiva para o jornalismo local, que considera as pessoas como sujeitos ativos da sociedade, a diversidade de contextos sociais e a necessidade de aprofundamento do debate público. A partir da perspectiva do materialismo histórico dialético, o Jornal Dois busca noticiar os fatos a partir dos contextos históricos, políticos, culturais e econômicos, compreendendo as complexidades, as contradições e as desigualdades étnico-racial, social e de gênero da sociedade. A experiência do Jornal Dois mostra que é possível desenvolver um projeto de jornalismo no interior levando em conta a pluralidade de narrativas, a diversidade de contextos, além da importância de se arquitetar uma rede solidária de informação.

Palavras-chave: Jornalismo; Mídia radical; Diversidade.

\footnotetext{
Abstract: This article proposes a reflection about the plurality in journalistic coverage in the interior of São Paulo State related from the Jornal Dois's experience. This news media came up with a disruptive proposal for local journalism which considers each person as an active individual on society, the diversity of social contexts and the need to deepen public debate. From the perspective of dialectical historical material, Jornal Dois seeks to report on historical facts, considering political, cultural and economic contexts, understanding the complexities and the contradictions of society, such as ethnic, racial, social and gender inequality. The experience

${ }^{1}$ Jornalista e mestranda pelo Programa de Pós-Graduação em Mídia e Tecnologia (PPGMIT) pela Universidade Estadual Paulista (UNESP). Pesquisa economia criativa, com foco nos arranjos produtivos de mulheres negras empreendedoras no Núcleo de Estudos e Observações em Economia Criativa (NeoCriativa). Cofundadora e repórter do Jornal Dois - mídia independente de Bauru.

2 Jornalista formado pela Universidade Estadual Paulista (UNESP) e repórter do Jornal Dois.

${ }^{3}$ Jornalista formado pela Universidade Estadual Paulista (UNESP) e repórter do Jornal Dois.
} 
of Jornal Dois shows that it is possible to develop a journalism project in the interior, considering a diversity of scenarios, social movements and the plurality of narratives, in addition to building a solidary information network.

Keywords: Journalism; Radical media; Diversity.

\section{Introdução}

A atuação do Jornal Dois em Bauru está inserida em um contexto de concentração da cobertura jornalística por grandes empresas e de esvaziamento do debate público. As reportagens e notícias feitas por veículos de comunicação tendem a não dialogar com a realidade do município, e é possível observar uma lacuna na produção de conteúdos noticiosos que refletem os contextos sociais, culturais, históricos, econômicos e políticos da população bauruense.

A cidade de Bauru possui cerca de 370 mil habitantes e está no centro-oeste do estado de São Paulo. O município se desenvolveu com a expansão da ferrovia pelo interior do Brasil. Ainda no início do século XX, a Estrada de Ferro Sorocabana, a Estrada de Ferro Noroeste do Brasil e a Companhia Paulista de Estradas de Ferro se cruzavam no território de Bauru, tornando a cidade o maior entroncamento ferroviário do país.

Parte de um processo de urbanização a nível nacional, o desenvolvimento da cidade como importante polo regional trouxe indústrias e trabalhadores de diversas regiões do país. Esse movimento traduziu-se na geografia de Bauru por meio da rápida expansão de sua malha urbana. Após o dinamismo da cidade nos tempos da ferrovia - que chegou a lhe render o epíteto de "cidade sem limites" -, Bauru sofreu os impactos da decadência desse modal de transporte durante as décadas de 1980 e 1990.

Nas duas primeiras décadas do século XXI, a demografia da cidade apontava para uma explícita segregação socioespacial e uma desigualdade de renda e de oportunidades para os cidadãos. Cerca de um terço da população está abaixo da linha da pobreza e depende de programas assistenciais da União, do Estado ou da prefeitura para sobreviver. Assim como em outras cidades de médio e grande porte, muitos bairros carecem de infraestrutura pública de urbanização: pavimentação, saneamento básico, iluminação, equipamentos públicos.

A terra e a moradia transformadas em ativos negociáveis aprofundaram os problemas sociais, como a expansão do programa Minha Casa Minha Vida pelas periferias, a comercialização de lotes em condomínios de alto padrão e a gentrificação de bairros inteiros - 
processo que reforça e alarga a vulnerabilidade social e a degradação ambiental, esta em geral associada à abertura de bairros informais e acampamentos.

\section{Jornalismo em Bauru}

Esse cenário complexo é reportado diariamente por veículos de comunicação ligados a grupos empresariais. Há mais de seis anos, apenas um jornal impresso circula pela região - o Jornal da Cidade. Na televisão, retransmissoras de redes nacionais, como a TV Tem (afiliada da Rede Globo), a Record Paulista e o SBT (com sede em Jaú), dividem o espaço com iniciativas menores, como a TV Prevê e a TVC - emissoras locais.

Os meios de comunicação mais abrangentes em alcance, as rádios, estão presentes com emissoras comerciais e públicas. Destas, Rádio Unesp e Rádio Câmara apresentam programação jornalística e musical. Esse formato também é encontrado nas rádios comerciais 87FM, 96FM, 94FM, Top FM e Jovem Pan.

Também existem iniciativas on-line que se propõem a fazer jornalismo, como o site de entretenimento Social Bauru, com matérias sobre eventos e entrevistas com personalidades bauruenses, e o G1 Bauru, portal de notícias da TV Tem com cobertura de Bauru e região "em tempo real".

Outro exemplo de mídia são páginas e perfis em redes sociais que fazem a divulgação de notícias sobre a cidade, mas sem o rigor da apuração jornalística. Na prática, esses canais são informativos e servem como plataforma de denúncia de ocorrências no trânsito e violência policial, reclamações do transporte público ou da saúde.

Observa-se, nesse sentido, uma lacuna na cobertura noticiosa dos meios de comunicação tradicionais de Bauru, que expõe a insuficiência de conteúdos que dialoguem com a realidade do município. Esse espaço é apropriado por mídias não jornalísticas, que trazem abordagens e informações do cotidiano bauruense sem o rigor da apuração jornalística.

\section{Sobre o Jornal Dois}

O Jornal Dois é um veículo de comunicação independente, sem fins lucrativos nem vínculos comerciais com empresas. Foi lançado em novembro de 2017, com uma equipe inicial de oito pessoas: sete formadas no curso de jornalismo da Unesp e um designer graduado na mesma instituição. 
O conceito que orientou os trabalhos do jornal foi o da Mídia Radical, teoria que explica a utilização dos meios de produção e a publicação de conteúdos para alcançar a raiz dos problemas feitas de forma disruptiva com o que havia até então estabelecido na mídia e no jornalismo locais.

Entende-se por mídia radical qualquer mídia desenvolvida em pequena escala sob diversos prismas e manifestações, sejam artísticas, culturais, digitais ou jornalísticas. Enquadram-se nesse contexto, por exemplo, teatros de rua ou em espaços culturais alternativos, danças, rádios livres, fanzines, camisetas e produções audiovisuais (DOWNING, 2002, p. 3730).

Apesar de muitas vezes estar associada a movimentos disruptivos, é possível identificar mídias com essas mesmas características que tenham posicionamento reacionário, racista, xenófobo e LGBTfóbico,

O Jornal Dois assume editorialmente uma posição política, como forma de deixar transparente os pressupostos que guiam as coberturas e a orientação que vai determinar os enquadramentos, as perspectivas e os focos adotados em reportagens e outros materiais. A linha editorial assume uma posição anticapitalista a partir de uma perspectiva “democrático-popular", formulação que ganhou repercussão no Brasil a partir do $5^{\circ}$ Encontro Nacional do PT, em 1987, e que atualmente abrange amplos setores da esquerda brasileira.

A forma de compreensão da realidade está baseada no materialismo histórico dialético - método que possibilita noticiar fatos considerando seus contextos históricos, políticos, culturais, sociais e econômicos, entendendo que a sociedade é complexa, contraditória, está calcada na desigualdade étnico-racial, social e de gênero, e que as relações concretas da vida em sociedade são o ponto-chave para compreender a ação humana na história.

O Jornal Dois assume como epistemologicamente inalcançáveis as categorias de isenção, imparcialidade e neutralidade, seja para o jornalismo ou para qualquer outro ramo da atividade humana. Considerando isso, a cobertura jornalística é orientada pelas premissas da objetividade, ou seja, a precisão e o rigor na apuração e na descrição dos fatos, buscando explorar a ambiguidade dos acontecimentos na vida das pessoas.

Como afirma Perseu Abramo (2016, p. 8), as qualidades de neutralidade, isenção e imparcialidade são categorias do comportamento moral por se situarem no campo da ação; a objetividade está no campo do conhecimento, ou seja, é uma categoria gnoseológica e epistemológica, configurando o processo de conhecimento humano, a chamada "cognoscibilidade". 
Nesse sentido, o que existe de objetivo na realidade concreta são os fenômenos enquanto manifestação indeterminada de significado. A apreensão dos fenômenos vem do seu relacionamento e enquadramento com a totalidade, no sentido marxista, da compreensão do complexo econômico, social e político em que está situado. Essa totalidade "se abre em possibilidades, cuja concretização depende dos sujeitos" (GENRO FILHO, 1987, p. 49). A concretização subjetiva, necessariamente, vai trazer algum grau de adesão a determinadas possibilidades de totalidade histórica.

A produção jornalística do Jornal Dois é, então, voltada para as classes populares da sociedade bauruense. Fazem parte do público trabalhadores; estudantes; pessoas ligadas a sindicatos, movimentos sociais, grupos; artistas e coletivos culturais, políticos e esportivos.

\section{Critérios de noticiabilidade}

O Jornal Dois não se apresenta como um contraponto ao que é reportado pela mídia empresarial da cidade, nem pretende meramente trazer uma outra opção de informação, concepções que se ligam ao conceito de mídia alternativa.

Em um contexto de censura econômica vivido no Brasil, com a informação propagada a partir da propriedade privada dos meios de comunicação e com a falta de uma regulamentação das comunicações para fazer valer os dispositivos constitucionais, como a proibição de monopólio/oligopólio, as mídias independentes têm um papel de contrainformação, numa tentativa de "quebra de silêncio" e de refutação de mentiras (DOWNING, op. cit., p. 49).

A proposta do jornal se concentra em aprofundar e qualificar o debate público e diversificar os discursos que alimentam a informação jornalística. Esses objetivos amarram-se a partir da atuação de uma mídia radical, que utilizamos para ir a fundo na análise e compreensão dos fenômenos sociais, explorando os nexos causais objetivos entre as estruturas e as pessoas dentro de determinado enquadramento histórico.

Para isso, foi preciso estabelecer critérios próprios de noticiabilidade e de valor-notícia. As iniciativas de mídia radical ou independente, no geral, não dispõem de recursos nem de estrutura para uma cobertura sistemática do que ocorre no mundo. Esse é um importante filtro que vai ditar a escolha das pautas para os conteúdos: pessoas disponíveis.

O chamado "factual" - a notícia de momento, a cobertura diária sobre a cidade raramente aparece nas matérias do Jornal Dois. A produção pode reportar temas que já foram noticiados por outros veículos da cidade, mas vai trazer uma análise dos fatos (para o caso de terem sido pouco explorados na cobertura dos veículos empresariais), uma contextualização 
maior (por terem sido reportados de forma enviesada, segundo os interesses desses veículos) ou uma combinação das duas coisas.

As pautas factuais ocorrem quando dizem respeito aos temas em que o Jornal Dois busca se debruçar: movimentos sociais, manifestações, reintegrações de posse, por exemplo. Importante ressaltar que a própria carência de recursos materiais e humanos do Jornal Dois, além do maior tempo necessário para produzir conteúdo, fazem com que o foco não seja o fato em si, mas seus desdobramentos e implicações.

Este último é mais um fator que define a escolha das pautas: aquilo que é socialmente relevante e importante de ser noticiado para o público do Jornal Dois. Essas pautas são resultado da análise da realidade social da cidade e dos problemas que afetam a população mais pobre e vulnerável: especulação imobiliária, insuficiência de acesso à educação, de políticas públicas e de mobilidade urbana.

Para esse tipo de produção, é preciso uma investigação mais rigorosa, com levantamento de dados, muitas vezes via Lei de Acesso à Informação, entrevistas, apuração in loco, pesquisa em trabalhos científicos e na legislação. As demais pautas são de "nicho" - temas que são pouco ou nada abordados pela mídia comercial. Grandes vertentes dessa temática são as produções sobre a efervescente cultura independente e popular de Bauru, como as movimentações de hiphop, carnaval, funk, sarau, slams, batalha de rima, performance de teatro, maracatu. Outro assunto abordado é o futebol amador, com a cobertura de jogos e do meio social do qual fazem parte jogadores, dirigentes de clubes e torcedores.

Como aponta Downing (op. cit., p. 33), "várias formas de mídia radical alternativa são, de maneira quase óbvia, formas de expressão das culturas populares e de oposição”.

\section{A pauta, o conteúdo e as redes sociais}

O documento que orienta a produção de conteúdo no Jornal Dois é pensado por meio de quatro contextualizações: macroambiente, ambiente, microambiente e nanoambiente. A metódica para elaborar a pauta foi desenvolvida pelo Prof. Dr. Juarez Xavier ${ }^{4}$. Cada uma dessas categorias possibilita uma análise sobre o tema da pauta e funciona como uma espécie de funil para elencar as influências e compreender o fenômeno a ser reportado.

\footnotetext{
${ }^{4}$ Juarez Tadeu de Paula Xavier é docente no curso de jornalismo e no programa de Pós-Graduação de Mídia e Tecnologia da Faculdade de Arquitetura, Arte e Comunicação da Universidade Estadual Paulista (FAAC/Unesp) em Bauru.
} 
O exercício de elaboração e reflexão sobre a pauta é fundamental para o desenvolvimentos das reportagens aprofundadas, e cada categoria tem uma abordagem específica. O macroambiente é a interlocução do assunto com os debates a nível global, relacionando-o com as repercussões internacionais. $\mathrm{O}$ ambiente faz a ancoragem da discussão no cenário nacional e elucida os pontos de conexão daquele tema com abordagens políticas, econômicas e sociais. Já o microambiente vincula o assunto ao espaço onde ocorre o fato, trazendo a discussão para o nível local. Por fim, o nanoambiente considera as peculiaridades e as interferências do território, que tornam o fenômeno abordado inédito.

As reportagens aprofundadas partem da observação da singularidade do fato para a abertura para a universalidade. Há a preocupação de explicar o que aquele acontecimento simboliza para as pessoas e quais as consequências do ocorrido no cotidiano. O exercício da revelar as circunstâncias do acontecimento faz parte do processo de humanização da notícia.

A produção do Jornal Dois está dividida entre textos e vídeos. A opção pelo formato dialoga com a estrutura da pauta: se o conteúdo for a cobertura de um evento, uma atividade cultural ou esportiva, ou o dia a dia do bauruense, a linguagem escolhida é a audiovisual; se a matéria demandar ampla contextualização, análise de bases de dados, de cenário político e do ineditismo do fato, o formato é o texto.

Para as reportagens escritas é necessário explorar as relações nacionais e locais do assunto. Esse é o recurso utilizado para produzir matérias dialógicas, com relações direta com a realidade e que fujam dos padrões de manipulação da informação apresentados por Abramo (2016, p. 39). São exemplos as reportagens sobre a ação da Polícia Militar no combate ao tráfico de drogas ${ }^{5}$, o desenvolvimento urbano da gestão atual de Bauru ${ }^{6}$ e a desmatamento do cerrado paulista ${ }^{7}$.

Vale destacar a importância dos vídeos no alcance do jornal. O YouTube divulgou no Brandcast 2018 (evento que ocorre anualmente para divulgar dados sobre a plataforma) que o Brasil aumentou, de 2014 a 2018, em 135\% o consumo de vídeos na internet, superando a média de 19 horas semanais. A produção de conteúdos audiovisuais, apesar de apresentar limitações para aprofundar os debates e explorar as questões estruturais da sociedade, se aproxima de uma

\footnotetext{
5 "Raça, droga e rua: o mapa do tráfico em Bauru". Disponível em: http://jornaldois.com.br/raca-droga-e-rua-omapa-do-trafico-em-bauru/. Acesso em: 24 jun. 2020.

6 "Papo reto pra Bauru ficar perfeita: o que é o 'destravamento' da cidade?". Disponível em: http://jornaldois.com.br/papo-reto-pra-bauru-ficar-perfeita-o-que-e-o-destravamento-da-cidade/. Acesso em: 24 jun. 2020.

7 "Ser radical é ter menos de 1\% do Cerrado e querer desmatar", diz presidente da SOS Cerrado Bauru. Disponível em: http://jornaldois.com.br/ser-radical-e-ter-menos-de-1-do-cerrado-e-querer-desmatar-diz-presidente-da-soscerrado-bauru/. Acesso em: 24 jun. 2020.
} 
representação fiel da vida das pessoas, explorando as subjetividades. Registrar, por meio de imagens, grupos que nunca antes apareceram em canais de televisão e vídeos na internet é significativo para as pessoas, que se veem como sujeitos das ações.

O audiovisual é uma inovação em Bauru tanto pelo modelo de vídeo praticado quanto pelas temáticas registradas. As produções do Jornal Dois utilizam-se da linguagem documental para relatar a situação abordada e visibilizar os sujeitos envolvidos. $\mathrm{O}$ vídeo não tem texto em off - a narração fica por conta dos depoimentos dos entrevistados, que vivenciam a realidade. Informações técnicas são adicionadas com texto em destaque na cena. E a trilha sonora, indispensável nos produtos audiovisuais, é responsável por capturar a subjetividade do tema.

A interlocução com atores políticos da cidade de Bauru é um meio fundamental para o desenvolvimento dos conteúdos. Exemplo disso é a reportagem "Nova Canaã: MSLT encaminha mais um assentamento para a maior ocupação da história de Bauru" ${ }^{8}$. A matéria aborda transferências de assentados de diferentes regiões da cidade para um local comum e a organização dos militantes do MSLT (Movimento Social de Luta dos Trabalhadores) para a mudança. Assuntos relativos à burocracia do planejamento urbano, às tramitações judiciais e aos projetos políticos são trabalhados de forma a aprofundar o entendimento da situação e oferecer ao leitor diversos complexos envolvidos no fato.

Nessa reportagem, a compreensão do papel social desempenhado pelo movimento social foi indispensável para não cair em uma deslegitimação da sua atuação. O texto expõe conflitos internos entre moradores do assentamento e até relatos desencontrados sobre a ação de lideranças do movimento, como uma suposta cobrança de contribuição financeira mensal.

Por ser uma mídia digital, o Jornal Dois se apropria das redes sociais para potencializar a divulgação das matérias. A internet possibilitou a realização do projeto como veículo de comunicação ao facilitar a produção jornalística e reduzir os custos da divulgação dos conteúdos. Além do site, o Jornal Dois está presente nas principais redes sociais (Facebook, Instagram, YouTube, Twitter e WhatsApp). Todo material produzido é compartilhado no site e replicado no perfil de cada rede. Nessas plataformas, forma-se a comunidade do Jornal Dois uma cadeia de apoiadores e leitores que sustentam o projeto.

\footnotetext{
8 "Nova Canaã: MSLT encaminha mais um assentamento para a maior ocupação da história de Bauru”. Disponível em: http://jornaldois.com.br/nova-canaa-mslt-encaminha-mais-um-assentamento-para-a-mai or-ocupacao-dahistoria-de-bauru. Acesso em: 24 jun. 2020.
} 


\section{Capilaridade}

Considerando toda a concepção teórica elaborada ao longo de quatro meses sobre a atuação do Jornal Dois na cidade, foi preciso buscar formas de colocar em prática um jornalismo que, além de alinhado politicamente com as demandas da sociedade bauruense, dialogasse com as pessoas. Inútil seria um jornalismo dito "propositivo" que não esteja presente nos lugares e que se limite à busca pela leitura de uma realidade complexa. Uma equipe de reportagem que não compreende a vida da população, em sua maioria, apresenta deficiências cognitivas no trabalho jornalístico.

Para tanto, a principal maneira encontrada pelo Jornal Dois foi estreitar os laços com os movimentos sociais da cidade. Não de forma afetiva, mas ativamente participativa na organização, na articulação e nas ações propostas por estes setores. A parceria com os movimentos estabeleceu uma relação de confiança no trabalho do Jornal Dois, a ponto de a população buscar o veículo para encaminhar denúncias e propostas de pautas, entendendo o jornal como a única mídia interessada em pautar essas questões.

O contato quase que diário com os grupos organizados criou essa relação repórter-fonte que é fundamental em uma cobertura propositiva. $\mathrm{O}$ acesso aos espaços que a mídia hegemônica não toca no dia a dia é decorrente dessa relação.

A forma de retratar as pessoas e dar visibilidade para as ações organizadas também foi um ponto crucial para a aproximação com o público e a disseminação dos conteúdos em parte da população. Focar no protagonismo dos indivíduos, por meio de textos e vídeos, é o principal aspecto de uma cobertura que consegue abordar os desafios dos grupos marginalizados.

\section{Considerações finais}

Comunicar para e com os públicos é um dos desafios do jornalismo. Pensar a comunicação e a produção de conteúdo de forma dialógica e propositiva demanda tempo para apuração e reflexão sobre os cenários e fatos. Essa é a prática que o Jornal Dois tem adotado desde o princípio. O compromisso com o jornalismo ético e de qualidade, com a valorização de narrativas contra-hegemônicas, com a diversidade de pessoas e seus contextos plurais.

$\mathrm{Na}$ internet, o fazer jornalístico ganhou novas configurações, que estão além do forma e do conteúdo - e da relação do jornal com o público. Conectar-se com os leitores e apoiadores é o modo como se constrói uma comunidade que se fortalece mutuamente. Na grande mídia, composta pelas empresas de comunicação, as reportagens elaboradas a partir da relação indireta 
com a realidade retroalimentam uma perspectiva de fabulação. A experiência do Jornal Dois mostra que é possível arquitetar uma rede solidária de informação, na qual o apoio é recíproco.

\section{Referências bibliográficas}

ABRAMO, Perseu. Padrões de manipulação na grande imprensa. 2. ed. São Paulo: Editora Fundação Perseu Abramo, 2016. 88p.

DOWNING, John. Mídia Radical: rebeldia nas comunicações e nos movimentos sociais. Trad.: Silvana Vieira. São Paulo: Editora Senac São Paulo, 2002. 544p.

FREIRE, Paulo. Educação como prática da liberdade. 2. ed. Rio de Janeiro: Paz e Terra, 1967.

GENRO FILHO, Adelmo. O segredo da pirâmide - para uma teoria marxista do jornalismo. Porto Alegre: Tchê, 1987. 230p.

LAGE, Nilson. Teoria e técnica do texto jornalístico. Rio de Janeiro: Elsevier, 2005. 188p.

MARINHO, Maria Helena. Pesquisa Video Viewers: como os brasileiros estão consumindo vídeos em 2018. Disponível em: www.thinkwithgoogle.com/intl/pt-br/tendencias-de-consumo/pesquisavideo-viewers-como-os-brasileiros-estao-consumindo-videos-em-2018/. Acesso em: 14 maio 2020.

MBEMBE, Achille. Necropolítica: biopoder, soberania, estado de exceção, política da morte. Revista Arte \& Ensaios, Rio de Janeiro, n. 32, p. 123-151, dez. 2016.

PREFEITURA MUNICIPAL DE BAURU. Plano Diretor Participativo. 2008. Disponível em: http://hotsite.bauru.sp.gov.br/arquivos/website_planodiretor/ website_planodiretor_etapas.pdf. Acesso em: 13 maio 2020.

SANTOS, Milton. Por outra globalização: do pensamento único à consciência universal. Rio de Janeiro: Record, 2000. 85p. 